\title{
The Necessary Shifting to Improve Health Care Systems: Underdeveloped Countries
}

\author{
Innocent J Macha* \\ Department of Mechanical and Industrial Engineering, Dar es Salaam, Tanzania \\ *Corresponding author: Innocent J Macha, Department of Mechanical and Industrial Engineering, Dar es Salaam, Tanzania
}

\section{ARTICLE INFO}

Received: 幽 August 08, 2019

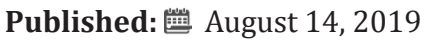

Citation: Innocent J Macha. The Necessary Shifting to Improve Health Care Systems: Underdeveloped Countries. Biomed J Sci \& Tech Res 20(4)-2019. BJSTR. MS.ID.003473.

\begin{abstract}
The primary use of life is living, a logical argument that has different realities in high and low-income settings. Poor people are just trying to survive due to mainly poor health care systems. Unfortunately, any development plan with health care gaps in it will potentially fail. It is high time now for the developing countries to review their commitment to improving adequate access to medical attention. Local development of drugs is suggested as the best option for sustainable health care and development in developing countries.
\end{abstract}

\section{In the Perspective}

The concern on inadequate access to essential medicines for the least developing countries has raised awareness of the situation and the need for sustainable solutions. Though for the last two decades have been some improvements in health care such as preventing about 7 million deaths from malaria and the half drop of mortality rate, there are still a billion people around the word with no access to medical attention. WHO reported that $95 \%$ of essential medicines are off-patent products [1]. The patent issue is not one of the barriers to essential medicines affordability and accessibility. The question to developing countries is why are the essential medicines not adequately accessible? Having the ability to buy medicines doesn't guarantee accessibility. It has been urged that the lack of efficient health infrastructures, political will or stability compounded by lack of access to clean water, hunger, and malnourishment hinder the accessibility of adequate medical attention in developing countries [2].

A two-year UNIDO global project provided technical cooperation to advance local pharmaceutical production in developing countries aimed at removing key systemic constraints such as lack of finance, technology and access to markets. This strategy leads to industrialization and should be embraced by developing countries to improve their health services. Local production of not only essential medicines but also vaccines and basic medical supplies will boost and sustain the current inefficient health systems in developing countries. Some of the big pharmaceutical companies are less interested in investing in diseases affecting poor people. On the other hand, pharmaceutical giants Johnson \& Johnson and GlaxoSmithKline PLC have changed their strategies in the developing world. They want to increase access to their medicines through relaxed patent protections and expanded partnerships with local health care providers. It looks like in the future health care of underdeveloped countries will be in their own hands. With this in mind, developing countries should first establish effective regulations in areas such as medicines prices and safety before embarking in local productions. Health systems should also undergo extensive refinement to improve medicines affordability, availability, and sustainability of the pharmaceutical industries.

India has set an excellent example for drug production and developing countries should try to do the same. India produces generic drugs, which in principle is the same as an existing approved brand name in terms of dosage, route of administration, strength, safety, quality, and performance characteristics [3]. Generic drugs are relatively cheap and they provide an opportunity for improving drug accessibility and availability as well as for saving healthcare expenditure because the generic drug manufacturers only formulate drugs when the patent and its exclusivity rights of the innovator are 
expired [4]. A great opportunity for developing countries to invest in their own drug manufacturing companies and reduce the heavy burden of drug importation. Currently, more than $70 \%$ of medical supplies of developing countries are being imported. Even the basic supplies that could be manufactured locally because of the abundant availability of raw materials like wound dressings are as well imported! Any serious government regardless of its GDP can still invest in the local medical supplies manufacturing. The amount of money poor countries spent to import medical supplies is huge and could be used otherwise.

It is envisaged that most of the developing countries should re-evaluate the performance of their health systems based on the United Nations Sustainable Development Goals [5] so that to renew their commitment to improving health as a central component of development. The current movements of poor countries shifting from low income to middle-income economy with an emphasis in industrialization, pharmaceutical industries among others, should be at the top of their list. In its development vision [6], Tanzania as a developing country, her aspirations among others, is to transform into a middle-income country by 2025 . With her five main national attributes in the vision, their success entirely depends on the improved health system. How much the development vision has considered health as an integral part of the plan is yet to be realized.

\section{Reference}

1. (2017) WHO. WHO Model List of Essential Medicines 2017.

2. Frost LJ, Reich MR (2009) Creating Access to Health Technologies in Poor Countries Health Affairs 28(4): 962-973.

3. (2018) FDA. Generic Drug Facts 2018.

4. Joshi SS, Shetty YC, Karande S (2019) Generic drugs - The Indian scenario J Postgrad Med 65(2): 67-69.

5. Kieny MP, Bekedam H, Dovlo D, Fitzgerald J, Habicht J, et al. (2017) Strengthening health systems for universal health coverage and sustainable development Bull World Health Organ 95(7): 537-539.

6. Commission TP. The Tanzania Development Vision 2025. 1990.
ISSN: 2574-1241

DOI: 10.26717/BJSTR.2019.20.003473

Innocent J Macha. Biomed J Sci \& Tech Res

CC (P) This work is licensed under Creative

Submission Link: https://biomedres.us/submit-manuscript.php

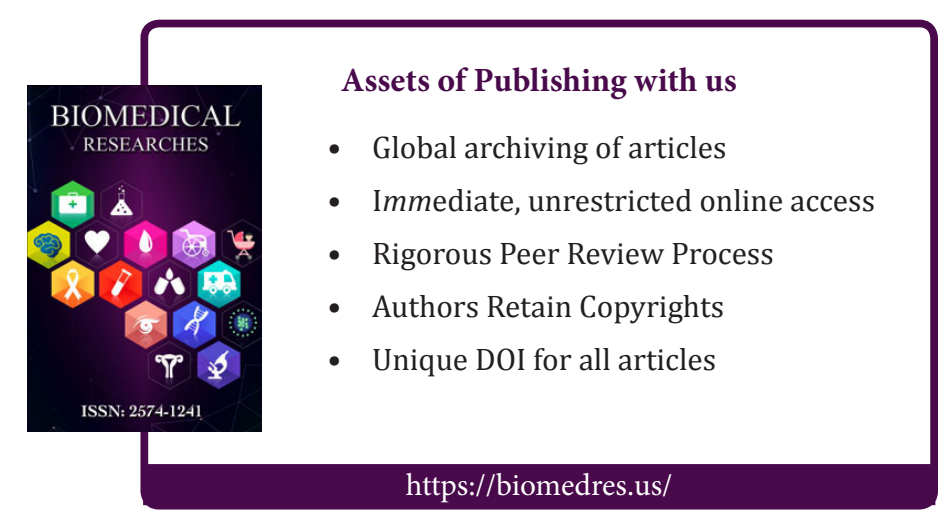

